\title{
Ear syringing improved hearing in general practice
}

Memel D, Langley $C$, Watkins $C$, et al. Effectiveness of ear syringing in general practice: a randomised controlled trial and patients' experiences. BrJ Gen Pract 2002;52:906-11.

\section{QUESTION: In general practice, does ear syringing improve hearing thresholds?}

\section{Design}

Randomised \{allocation concealed $\}^{*}$, blinded (outcome assessors), controlled trial with immediate follow up.

\section{Setting}

Ear syringing clinics at 3 general practices in the Bristol area, UK.

\section{Patients}

116 patients who attended the clinics with an ear drum completely obscured by wax and had instilled oily ear drops for $\geq 3$ days before syringing. 114 patients $(98 \%)$ were included in the analysis (mean age $63 \mathrm{y}, 54 \%$ men).

\section{Intervention}

All patients had a first hearing test. 55 patients allocated to the intervention group immediately had their ears syringed, waited until they were dry, and then had a second hearing test. 61 patients allocated to the control group waited an equivalent length of time before having a second hearing test, and then had their ears syringed.

\section{Main outcome measure}

Improvement in hearing threshold of $\geq 10 \mathrm{~dB}$ assessed by fully qualified audiologists using pure tone audiometry. Improvement was defined as the average change across 4 frequencies in the syringed ear or, if both ears were syringed, in the ear that improved more.

\section{Main results}

21 patients in the intervention group had 1 ear syringed, and 32 had both ears syringed. More patients in the intervention group had improvements in hearing of $\geq 10 \mathrm{~dB}$ than in the control group (table). Mean difference in improvement between the 2 groups was $6.9 \mathrm{~dB}(95 \%$ CI 3.8 to 10.1$)$.

\section{Conclusion}

Ear syringing improved hearing thresholds in general practice.

*Information provided by author.

\section{Ear syringing $v$ no syringing in general practice ${ }^{\dagger}$}

\begin{tabular}{lllll} 
Outcome & Syringing syringing & $\begin{array}{l}\text { RBI } \\
(95 \% \mathrm{Cl})\end{array}$ & $\begin{array}{l}\text { NNT } \\
\text { (CI) }\end{array}$ \\
$\begin{array}{l}\text { l10 dB } \\
\text { improvement } \\
\text { in hearing }\end{array}$ & $34 \%$ & $1.6 \%$ & $\begin{array}{l}1972 \% \\
(275 \text { to } 11908)\end{array}$ & $\begin{array}{l}4 \\
\text { (3 to } 5)\end{array}$ \\
\hline
\end{tabular}

†Abbreviations defined in glossary; $\mathrm{RBI}$ and $\mathrm{Cl}$ calculated from data in article.

\section{COMMENTARY}

Ear syringing for removing wax that has occluded the eardrum is a common clinical procedure. Previous studies investigating the efficacy of ear syringing have assessed outcomes relating to the ease of syringing or clearance of wax, but it is generally understood that the reason to remove the wax is because it results in hearing loss.

Memel et al sought to determine if ear syringing improved hearing thresholds. Attention was paid to methods to reduce bias, such as random allocation of groups, similar treatment of groups except for the intervention, and blinding of the audiologists assessing the outcome, suggesting the result is likely to be reliable. The main outcome was an improvement in hearing threshold of $\geq 10$ $\mathrm{dB}$ as the average change across the $500 \mathrm{~Hz}, 1 \mathrm{kHz}, 2 \mathrm{kHz}$, and $4 \mathrm{kHz}$ frequencies. Considerably more patients in the intervention group than in the control group achieved such an improvement, but the mean difference in improvement was small $(6.9 \mathrm{~dB})$. The mean improvement was much larger among patients with $\geq 10 \mathrm{~dB}$ improvement in hearing thresholds ( $24 \mathrm{~dB}$ ), indicating that some patients benefited a lot, whereas others received no benefit. However, this study does not help to determine which patients will benefit most. Furthermore, from a clinical perspective it is not clear whether the treatment effect is a result of syringing alone. The initial hearing test appears to have been done after the ears were treated with oily drops, and thus the benefit of syringing might differ if wax drops are not used. Also, the findings may not be as applicable to young people as the study sample was relatively old (mean age $63 \mathrm{y}$ ), and some ear conditions are age related.

Ear syringing has risks, such as perforation of the eardrum, that can result in litigation. ${ }^{1}$ This has stimulated debate about the best method of removing wax. Unfortunately the study's sample size was too small to report conclusively on the adverse effects of syringing. Alternatives to syringing include suction debridement and disintegration by use of cerumenolytics, but these procedures also have adverse effects, such as irritation, and have not been adequately researched for effectiveness in vivo. ${ }^{2}$ Given the reported dangers of ear syringing, ${ }^{3}$ perhaps the procedure is advisable only in patients who had good hearing before a build up of wax. For patients who are unlikely to improve their hearing threshold with wax removal or those who are most vulnerable to further hearing loss (such as those with substantial impairment in one ear), use of cerumenolytics may be safer.

Gael Somerville, RGN, OHNC, MSc Occupational Health Nurse BBC Occupational Health Department London, UK

1 Price J. Problems of ear syringing. Practice Nurse 1997;14:126, 128.

2 Somerville G. The most effective products available to facilitate ear syringing. Br J Community Nurs 2002;7:94-101.

3 Grossan M. Safe, effective techniques for cerumen removal. Geriatrics 2000;55:80, 83-6. 